\title{
Gold nanoparticle-based biosensors
}

\author{
Yuanyuang $\mathrm{Li}^{\mathrm{a}}$, Hermann J. Schluesener ${ }^{\mathrm{b}}$, Shunqing $\mathrm{Xu}^{\mathrm{a} *}$ \\ www.goldbulletin.org
}

\begin{abstract}
The unique properties of gold nanoparticles have stimulated the increasing interest in the application of GNPs in interfacing biological recognition events with signal transduction and in designing biosensing devices exhibiting novel functions. The optical properties of GNPs provide wide range opportunities for construction optical biosensors. The excellent biocompatibility, conductivity, catalytic properties and high surface-to-volume ratio and high density of GNPs facilitate extensive application of GNPs in construction of electrochemical and piezoelectric biosensors with enhanced analytical performance with respect to other biosensor designs. In this article, the recent advances in construction of GNP-based optical, electrochemical and piezoelectric biosensors are reviewed, and some illustrative examples given, with a focus on the roles GNPs play in the biosensing process and the mechanism of GNPs for improving the analytical performances. Finally, the review concludes with an outline of present and future research for the real-world applications.
\end{abstract}

\footnotetext{
a Key Lab of Environment and Health, School of Public Health, Tongji Medical College, Huazhong University of Science and Technology, Wuhan 430030, China

b Institute of Brain Research, Hospital of Tuebingen University, Calwerstrasse 3, D-72076 Tuebingen, Germany

* Corresponding to: Shunqing Xu, Key Lab of Environment and Health, School of Public Health, Tongji Medical College, Huazhong University of Science and Technology, Wuhan 430030, China.

Tel: 862783657705 , Fax: 862783692333 ,

E-mail: shunqing@mails.tjmu.edu.cn
}

Keywords: gold nanoparticle, biosensor, optical sensor, electrochemical sensor, piezoelectric sensor

\section{Introduction}

Sensors are a class of devices that produce measurable responses to changes in physical conditions or chemical concentrations. In general, a sensor comprises a sensing element and a signal transducer, and produces a signal proportional to the analyte concentration. With the properties of high sensitivity, fast responds and low cost, the sensors continue to make significant impact, especially in biological and medical applications.

Biosensors - first reported in 1962 [1] - are generally defined as sensors that consist of biological recognition elements, often called bioreceptors, or transducers [2]. Biosensors have two basic principles different from conventional chemical sensors: (1) the sensing elements are biological structures, such as cells, enzymes, or nucleic acids; (2) the sensors are used to measure biological processes or physical changes. Owing to the constant desire for novel devices that offer higher sensitivity, greater analyte discrimination, and lower operating costs, intensive research efforts have been put to improve the sensing and transducing performance.

With the recent advances in nanotechnology, nanomaterials have received great interests in the field of biosensors due to their exquisite sensitivity in chemical and biological sensing [3]. Many kinds of nanoparticles, including metal nanoparticles, oxide nanoparticles, semiconductor nanoparticles, and even nanodimensional conducting polymers have been used in biosensors. For example, the use of gold and silver nanoparticles, or silver-silica hybrid nanostructures as biosensor substrates have been reported by several laboratories [4-6]. Some oxide nanoparticles and semiconductor nanoparticles such as $\mathrm{MnO}_{2}$ nanoparticles [7] and CdS nanoparticles [8] are also applied to construct biosensor. Owing to these unique properties, 
different kinds of nanoparticles always play different roles in different sensing systems. Generally, metal nanoparticles are always used as components of "electronic wires". Oxide nanoparticles are often applied to immobilize biomolecules, while semiconductor nanoparticles are often used as labels or tracers [9]. Among the nanomaterials used as component in biosensors, gold nanoparticles (GNPs) have received greatest interests because they have several kinds of intriguing properties [10, 11]. GNPs, with the diameter of 1-100 nm, have high surface-to-volume ratio and high surface energy to provide a stable immobilization of a large amount of biomolecules retaining their bioactivity. Moreover, GNPs have an ability to permit fast and direct electron transfer between a wide range of electroactive species and electrode materials. In addition, the light-scattering properties and extremely large enhancement ability of the local electromagnetic field enables GNPs to be used as signal amplification tags in diverse biosensors.

In this article, different types of GNP-based biosensors are reviewed with focus on GNPs that are immobilized. Thus, biosensors in which the GNPs are initially in suspension are not discussed herein, but without doubt they have potential in a variety of analyte detection (eg. The work by Liu and Lu on a colormetric lead biosensor using DNAzyme-directed assembly of GNPs [12] and the GNPs-based chemiluminescence system for DNA hybridization detection[13]).

With different types of signal transducers, the physical or chemical changes that occur during the binding of the analyte to the bioreceptors of biosensors can be transformed into optical, electrical, or qualitative output signals etc. According to these transductions, different types of GNP-based biosensors are considered separately in the review and some illustrative examples commented.

\section{GNP-based biosensors}

As described previously, GNP-based biosensors can be classified into optical biosensors, electrochemical biosensors and piezo-electric biosensors. In the following, an introduction into various types of GNP-based biosensors is presented. The roles that GNPs have played in the biosensing process and the mechanism of GNPs for improving the analytical performances are in the main focus (Table 1).

Table 1. Different functions of GNPs in biosensor systems

\begin{tabular}{|c|c|c|c|c|c|}
\hline $\begin{array}{l}\text { Types of } \\
\text { biosensors }\end{array}$ & $\begin{array}{l}\text { Principle of } \\
\text { detection }\end{array}$ & $\begin{array}{l}\text { Functions of } \\
\text { GNPs }\end{array}$ & $\begin{array}{l}\text { Properties } \\
\text { used }\end{array}$ & $\begin{array}{l}\text { Sensor } \\
\text { advantages }\end{array}$ & $\begin{array}{l}\text { Typical } \\
\text { examples }\end{array}$ \\
\hline \multirow[t]{2}{*}{$\begin{array}{l}\text { Optical } \\
\text { biosensor }\end{array}$} & $\begin{array}{l}\text { Changes in } \\
\text { optical properties }\end{array}$ & $\begin{array}{l}\text { Enhancement of } \\
\text { refractive index } \\
\text { changes }\end{array}$ & $\begin{array}{l}\text { large dielectric constant, } \\
\text { high density, high } \\
\text { molecular weight }\end{array}$ & Improved sensitivity & $\begin{array}{l}\text { DNA sensor with GNPs } \\
\text { responses } 1000 \text { times } \\
\text { more sensitive than } \\
\text { without [34]. }\end{array}$ \\
\hline & & $\begin{array}{l}\text { Enhancement of } \\
\text { electron transfer }\end{array}$ & $\begin{array}{l}\text { Conductivity, } \\
\text { quantum dimension }\end{array}$ & Improved sensitivity & $\begin{array}{l}\text { Electron transfer rate } \\
\text { of } 5000 \text { per second with } \\
\text { GNPs, while } 700 \text { per } \\
\text { second without GNPs [4] }\end{array}$ \\
\hline \multirow[t]{2}{*}{$\begin{array}{l}\text { Electrochemical } \\
\text { biosensor }\end{array}$} & $\begin{array}{l}\text { Changes in } \\
\text { electrical } \\
\text { characteristics }\end{array}$ & $\begin{array}{l}\text { Immobilization } \\
\text { platform }\end{array}$ & $\begin{array}{l}\text { Biocompatibility, } \\
\text { large surface area }\end{array}$ & $\begin{array}{l}\text { Improved sensitivity } \\
\text { and stability }\end{array}$ & $\begin{array}{l}\text { Glucose biosensor with } \\
\text { GNPs achieves } \\
\text { detection limit of } \\
0.18 \mu \mathrm{M} \text { [82]. }\end{array}$ \\
\hline & & $\begin{array}{l}\text { Catalysis of } \\
\text { reactions }\end{array}$ & $\begin{array}{l}\text { High surface energy, } \\
\text { interface-dominated } \\
\text { properties }\end{array}$ & $\begin{array}{l}\text { Improved sensitivity } \\
\text { and selectivity }\end{array}$ & $\begin{array}{l}\text { NADH sensor based on } \\
\text { GNPs shows } 780 \mathrm{mV} \\
\text { overpotential decrease } \\
\text { without any electron } \\
\text { transfer mediators } \\
\text { [114]. }\end{array}$ \\
\hline $\begin{array}{l}\text { Piezoelectric } \\
\text { biosensor }\end{array}$ & Changes in mass & $\begin{array}{l}\text { Biomolecule } \\
\text { Immobilization, } \\
\text { amplification of } \\
\text { mass change }\end{array}$ & $\begin{array}{l}\text { Biocompatibility, high } \\
\text { density, Large } \\
\text { surface-to-volume } \\
\text { ratio, }\end{array}$ & Improved sensitivity & $\begin{array}{l}\text { DNA sensor using } \\
\text { GNPs as amplification } \\
\text { tags with detection limit } \\
\text { of } 10^{-16} \mathrm{~mol} / \mathrm{L}[134]\end{array}$ \\
\hline
\end{tabular}




\subsection{GNP-based optical biosensors}

Optical biosensors generally measure changes in light or photon output. For optical biosensing utilizing GNPs, the optical properties provide a wide range of opportunities, all of which ultimately arise from the collective oscillations of conduction band electrons ("plasmons") in response to external electromagnetic radiation [14]. There are several optical sensing modalities for GNPs, and the surface plasmon resonance (SPR) is the one that attracted most intensive research. SPR, which is an optical phenomenon arising from the interaction between an electromagnetic wave and the conduction electrons in a metal, is used for probing and characterizing physicochemical changes of thin films on metal surface $[15,16]$. This resonance is a coherent oscillation of the surface conduction electrons excited by electromagnetic radiation. The binding of specific molecules onto the surface of metallic films can induce a variation in the dielectric constant, which can cause a change in the reflection of laser light from a metal-liquid surface (Fig.1) [15, 16]. GNPs, whose optical extinction spectrum is highly sensitive to the dielectric constant of the surrounding medium [17, 18], have been studied intensively in SPR to provide better analytical characteristics.

In 1998, Englebienne reported a red-shift of the SPR wavelength of colloidal gold particles coated by a monoclonal antibody [19]. He demonstrated that this shift originated neither from agglutination nor aggregation, but was due to a change in the refractive index of the individual particles subsequent

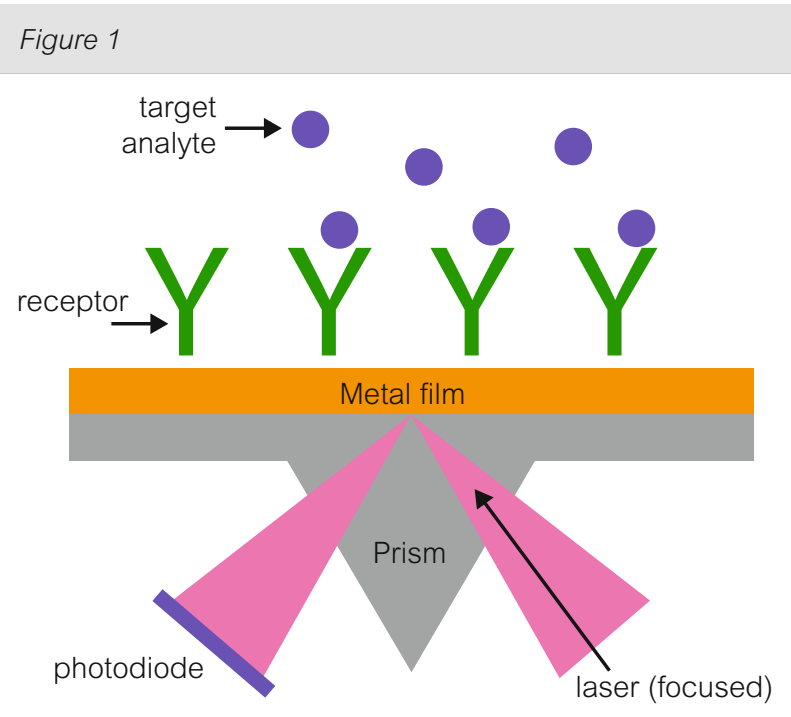

Schematic of surface plasmon resonance detection unit to further coating by the specific ligand when binding to the antibody. This finding was supported by two observations. Firstly, after incubation with a wide range of anti-human heart fatty acid-binding protein (hFABP) concentrations, the fixed amount of independently colloidal gold coated with identical concentrations of three monoclonal hFABP antibodies, which were definitely shown to recognize each a single independent epitope on the hFABP molecule, showed three completely different doseresponse relationships [19]. Secondly, the height of analytical response was inverse related to the affinity of the respective antibodies, which was consistent with the inversely proportional relationship between antibody affinity and binding capacity [20]. Since then, numerous labs have put effort into the work for correlating peak intensity and position of the surface plasmon absorbance of GNPs with the local refractive index of the surrounding medium [2131], which is termed the localized surface Plasmon resonance (LSPR).

GNPs are considered to have the ability to amplify the SPR signals [25, 32-42]. Lin et al. developed a fiber-based biosensor for organophosphorous pesticide determination utilizing the LSPR effect of GNPs [43]. By using a self-assembling technique, an acetylcholinesterase (AChE) layer was immobilized by covalent coupling onto the GNP layer. When suitable pesticides presented, the activity of AChE to hydrolyze acetylcholine chloride would be inhibited and lead to the change of the light attenuation due to a local increase of the refractive index. The concentration of pesticide could be determined based on the correlation between inhibition rate and light attenuation [43]. The comparative study of the fiber sensor with and without GNPs suggested that the GNPs coated on optical fiber can substantially enhance the sensitivity of the sensor [43]. A sensing method for the detection of DNA hybridization by GNP-enhanced SPR was demonstrated by $\mathrm{He}$ and colleagues [34]. Oligonucleotide probes were used to conjugate to colloidal Au particles and used to selectively recognize surface-confined target DNA via sequence-specific hybridization and GNPs were conjugated to the oligonucleotide probes as amplification tags. In the presence of GNPs, a greater than 1000-fold improvement of sensitivity over the unamplified methods was achieved [34]. Similarly, Li et al. developed a sensitive method for the analysis of single nucleotide polymorphisms (SNPs) in genomic DNA using GNP-enhanced surface plasmon resonance imaging (SPRI) [44]. In all these cases, the signal amplification mechanism 


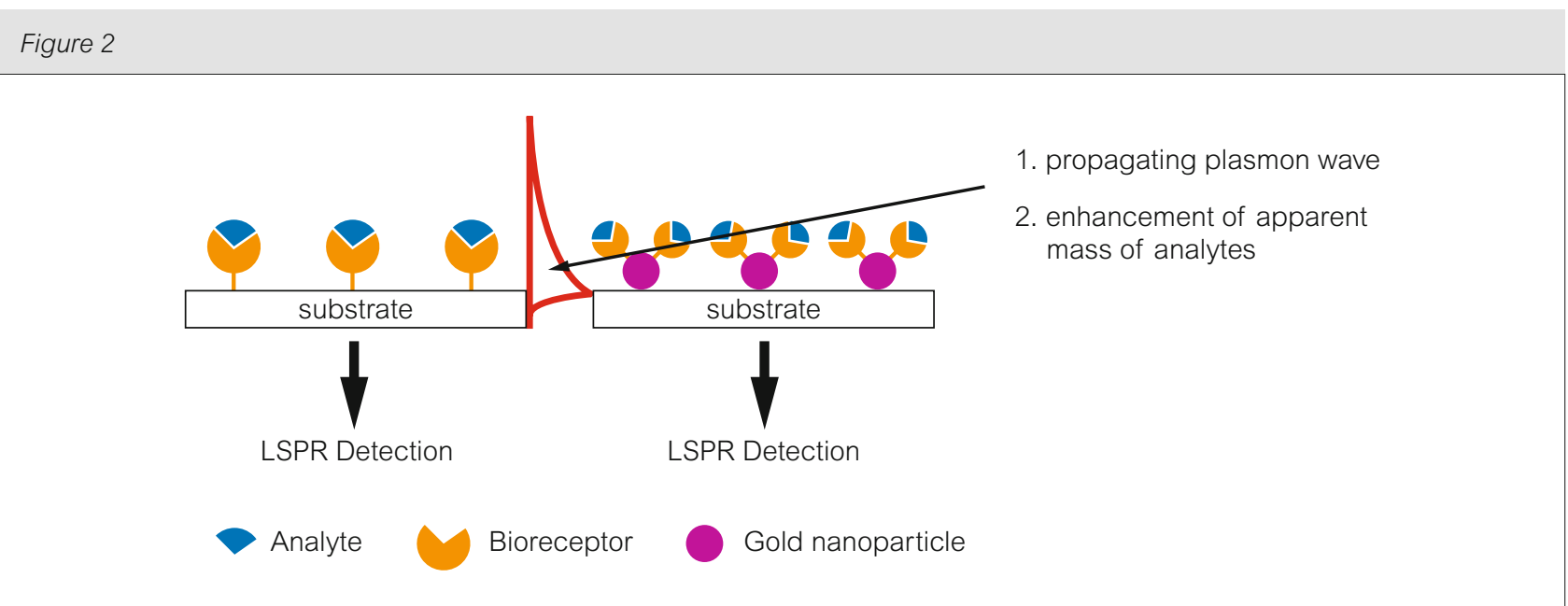

Signal amplification mechanism of GNPs in SPR biosensor. GNPs can also be immobilized on the substrate by bioreceptors and analytes (exp. DNA, not shown in the figure)

\section{Figure 3}

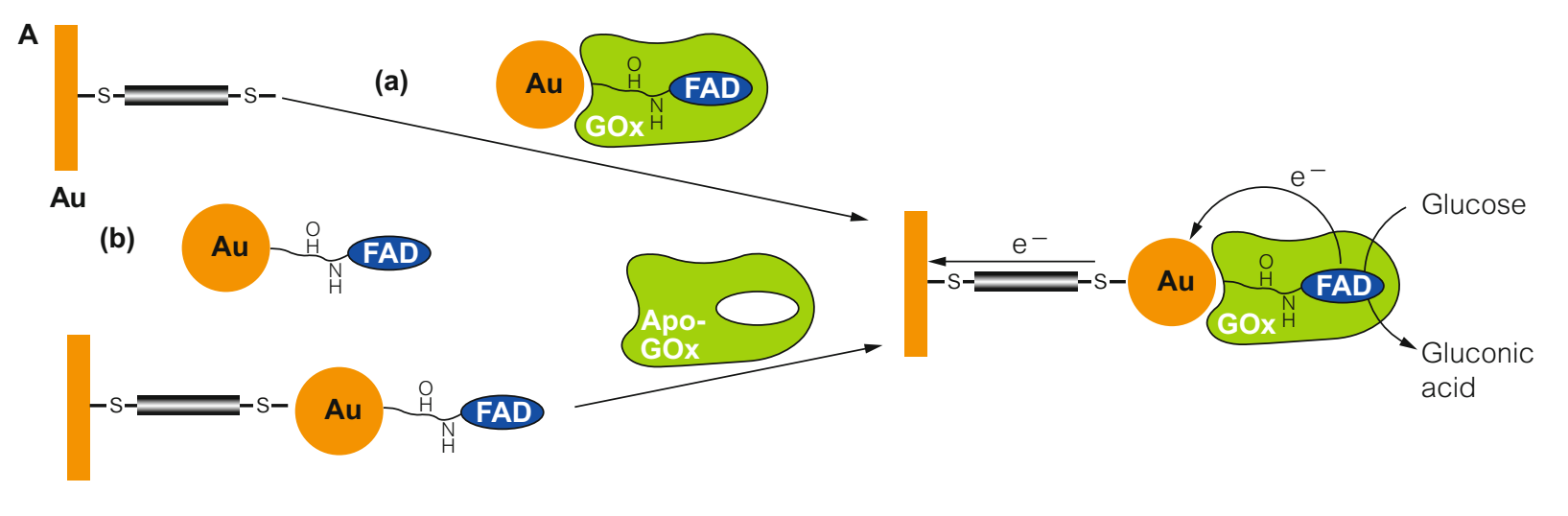

Two construction ways of GNP-reconstituted GO electrode, (a) adsorption of GNP-reconstituted GOx to a dithiol monolayer associated with a Au electrode; (b) adsorption of GPNs functionalized with FAD on the dithiol-modified Au electrode followed by the reconstitution of apo-GOx on the functional GNPs. (From [4]. Reprinted with permission from AAAS)

of GNPs can be generally summarized into two points (Fig. 2): (i) the electronic coupling between the localized surface plasmon of GNPs and the propagating plasmon on the SPR gold surface and (ii) the high density and high molecular weight of GNPs increase the apparent mass of the analytes immobilized on them. Based upon the signal amplification effect, Yang et al. developed a sensitive bioanalytical method for DNA detection utilizing catalytic growth of GNPs enhanced SPR [36].

It should be noted the GNP-based SPR biosensors can be fabricated into an array format, which enables rapid, high-throughput screening of biomoleclular interactions. Okamoto and colleagues demonstrated this type of biosensor in 2000 [26]. They measured the absorption spectra of the GNP monolayers in which GNPs were immobilized upon a glass slide by a functional organic coupling agent and found an optical response to polymers of different refractive indexes that were spin-cast on the immobilized GNPs [26]. Subsequently, a series of papers from different labs have presented this chip-based format optical biosensor, in which GNPs are immobilized on an optically transparent substrate [22, 23, 25, 45-49]. For instance, Matsui et al. demonstrated a SPR sensor chip for detection of small molecules like dopamine [47]. A dopamine-imprinted polymer gel with embedded GNP was fabricated on an allylmercaptan-modified gold substrate of a chip. 
They found the SPR signal of the chip was much higher than a chip immobilizing a lower density of GNPs or no GNPs. Consequently, it was concluded that the incorporation of GNPs into the molecularly imprinted polymer matrix substantially enhanced sensor sensitivity [47].

For most of the GNPs array SPR biosensors, sensing is generally based on the dependence of their SPR behaviors on either the refractive index of the surrounding media or the adlayer thickness or both [22, 23, 26]. Interestingly, Qi and co-workers demonstrated a humidity sensor based on the SPR sensitivity to the interparticle spacing other than to the surrounding refractive index or to the adlayer thickness [24]. In that sensor, GNP multilayer thin films were fabricated on polymethyl methacrylate substrates by using myoglobin as a linkage agent. With the ambient humidity changed, the alpha helical secondary structure myoglobin molecules changed, which meant the change of the molecular size of myoglobin. Thus, the interparticle spacing and thereby interparticle interaction changed, causing a change in the LSPR absorption of the multilayer thin film [24].

In addition to SPR-based biosensors, GNPs are also incorporated into other optical structures, for example, interferometer-based biosensors. Recently, a GNP-enhanced immune sensor based on fiber optic interferometry was reported by Tseng and co-workers [50]. Using a GNP-binding fiber, they demonstrated that an enlarged index mismatch and an elongated optical path by GNPs conjugated on recognition proteins contributed most to signal enhancement of the interference fringe shift. They also showed that the interference fringe shift was linearly related to both the amount and size of the GNPs [50]. Surfaceenhanced Raman scattering (SERS) is another optic transduction mode that can greatly benefit from the use of GNPs[51]. Cao et al. reported a multiplexed detection method of oligonucleotide targets used nanoparticles functionalized with oligonucleotides and Raman-active dyes [52]. The gold nanoparticles facilitated the formation of a silver coating that acted as a promoter for the Raman scattering of the dyes. High sensitivity down to the $20 \mathrm{fM}$ DNA level has been reported.

\subsection{GNP-based electrochemical biosensors}

Electrochemical biosensors, which convert the biological binding events into useful electrical signals, have received considerable attention in the past few years because they may provide fast, simple, and low-cost detection capabilities. Moreover, the use of GNPs for electrochemical biosensing arouses much research efforts [53]. The excellent biocompatibility, conductivity and catalytic properties make GNPs candidates to amplify the electrode surfaces, enhance the electron transfer between redox centers in proteins, and as catalysts to increase electrochemical reactions.

\subsubsection{GNPs act as electron transfer "electron wires"} In many bioelectrochemical reactions, the electron transfer between the redox-protein and the electrode surface is the key subject to be detected. However, the active centers of most oxidoreductases are surrounded by considerable thick insulating protein shells, and thus the electron transfer between electrodes and the active centers is blocked, resulting into poor analytical performances of electrochemical biosensing without electron transfer mediators. Some compounds, such as ferrocene derivatives [54], quinones [55], and poly-2-aminoaniline polymer [56] etc., were able to shuttle electrons. Interestingly, the conductivity properties of GNPs enhance the electron transfer between the active centers of proteins and electrodes and thus they act as electron transfer "electron wires". Natan's group have proved the direct electron transfer between the electrode and the protein by GNPs in 1996 for the first time [57]. They showed the direct, reversible cyclic voltammetry of horse heart cytochrome at 12-nm-diameter modified $\mathrm{SnO}_{2}$ electrode, without any pretreatment or polishing steps. They also found that the nanometer-scale morphology of metals was closely related to the protein electrochemistry. Since then, a series of papers has reported the electron communication between the biocatalysts and electrodes using GNPs as promoter [58-69]. Willner and co-workers studied the electron transfer turnover rate of a reconstituted bioelectrocatalyst using GNPs [4]. As shown in Fig. 3, they constructed a reconstituted GNP-glucose oxidase $\left(\mathrm{GO}_{\mathrm{x}}\right)$-monolayer electrode by two different ways: functionalizing $1.4 \mathrm{~nm}$ GNPs with $\mathrm{N}^{6}$-(2-aminoethyl)flavin adenine dinucleotide (FAD), reconstituting apo-GO ${ }_{x}$ with the FAD-functionalized GNP, and then assembling the $\mathrm{GNP}^{-\mathrm{GO}_{x}}$ on a gold electrode; or firstly assembling the FAD-functionalized GNP on the electrode and reconstituting apo- $\mathrm{GO}_{\mathrm{x}}$ subsequently. Both enzyme electrodes exhibited very fast electron transfer between the enzyme redox centre and the electrode in the presence of the gold nanoparticles. The electron transfer rate was found to be about 5000 per second, while the rate between glucose oxidase and its natural substrate, oxygen, was $\sim 700$ 
per second [4]. The excellent electron transfer ability of GNPs are due to an environment similar to that of redox proteins in native systems and give the protein molecules more freedom in orientation.

GNPs dispersed in polymeric matrices are also used to construct electrochemical biosensors with increased stability, improved processability, reusability and solubility in a variety of solvents [70]. The nanocomposite of GNPs and biopolymer, such as chitosan and poly (p-aminobenzene sulfonic acid) has been employed as an excellent matrix for fabricating novel biosensors [61, 71-74]. For instance, $\mathrm{Xu}$ and co-workers reported a nanocomposite composed of carboxymethyl chitosan and GNPs for $\mathrm{H}_{2} \mathrm{O}_{2}$ bioelectrochemical sensing [61]. The water-soluble nanocomposite provided horseradish peroxidase a stable, almost native and biocompatible environment, which promoted the direct electron transfer between horseradish peroxidase and the electrode. The biosensor exhibited a fast amperometric response (5s), a good linear response over a wide range of concentrations from $5.0 \times 10^{-6}$ to $1.4 \times 10^{-3} \mathrm{M}$, and a low detection limit of $4.01 \times 10^{-7} \mathrm{M}$ with good stability and sensitivity [61]. Furthermore, by immobilization of four different horseradish peroxidase-labeled antibodies modified GNPS on screen-printed carbon electrodes with chitosan/ sol-gel, Ju's group fabricated a disposable reagentless electrochemical immunosensor array, which implemented simultaneous multianalyte testing [75].

\subsubsection{GNPs act as immobilization platform}

The bioactivity, stability and quantity of the biological recognition elements immobilized on the electrode are important topics in bioelectrochemistry. Generally, the adsorption of biomolecules directly onto naked surfaces of bulk materials may frequently result in their denaturation and loss of bioactivity. The GNPs offer excellent candidates for the immobilization platform. The adsorption of biomolecules onto the surfaces of GNPs can retain their bioactivity and stability because of the biocompatibility and the high surface free energy of GNPs $[76,77]$. GNPs, as compared with flat gold surfaces, have a much higher surface area, allowing loading of a larger amount of protein and are potentially more sensitive. Thus, a number of labs have explored the contribution of GNPs for biomolecular immobilization [78-81]. For example, Andreescu et al. developed a sensitive and reagentless electrochemical glucose biosensor based on surface-immobilized periplasmic glucose receptors on GNPs [82]. The sensor was fabricated by immobilization of genetically engineered periplasmic glucose receptors to the GNPs, and showed selective detection of glucose in the micromolar concentration range, with a detection limit of $0.18 \mu \mathrm{M}$ [82]. Many similar studies have been reported for the construction of biosensors based on the immobilization of different proteins with GNPs, such as horseradish peroxidase [62, 83], microperoxidase-11 [84], tyrosinase [85] and human serum albumin [86]. Some biosensing elements are directly linked to the nanoparticles by the use of sulfur atoms within the bioentity [82], some are attached to the gold surface via thiol linkers [87, 88], and some are immobilized through covalent bonds [89], or amine groups [90].

In addition to enzyme [91] or antigen or antibody [81, 90, 92] immobilization, electrochemical DNA biosensors based on the immobilization of oligonucleotides with GNPs are also extensively studied. Generally, in order to bind to the GNPs, the oligonucleotides need modification with special functional groups that can interact strongly with GNPs. Thiol group are the most widely used groups for DNA and gold linkages [93, 94]. Kang and his colleagues immobilized thiol-modified probe oligonucleotides at the 5' phosphate end on the GNPs modified electrode surface [95]. Due to the high surface-to-volume ratio of GNPS, the hybridization amount of target DNA was greatly increased. Some other functional groups are also investigated. Fang and co-workers [96] immobilized an oligonucleotide with a mercaptohexyl-group at the 5'-phosphate end onto the $16 \mathrm{~nm}$ diameter GNPs, which were self-assembled on a cystamine-modified gold electrode. The saturated immobilization quantities of single-strand DNA on the modified electrode were about 10 times larger than that of a bare gold electrode.

GNPs are often conjugated with other nanomaterials to improve their binding capacity [97-99]. In this context, carbon nanotubes (CNTs) have attracted much interest due to their unique properties [100]. Nanohybrids of GNPs and CNTs offer a more effective immobilization matrix than that of GNPs alone. Cui et al. described a sensitive electrochemical biosensor with GNPs/ CNTs hybrids platform modified glass carbon electrode [101]. The CNTs were first activated and assembled on the electrode surface. Subsequently the GNPs were electrostatically adsorbed to the CNTs surface, followed by immobilization of the biosensing element, goat anti- 


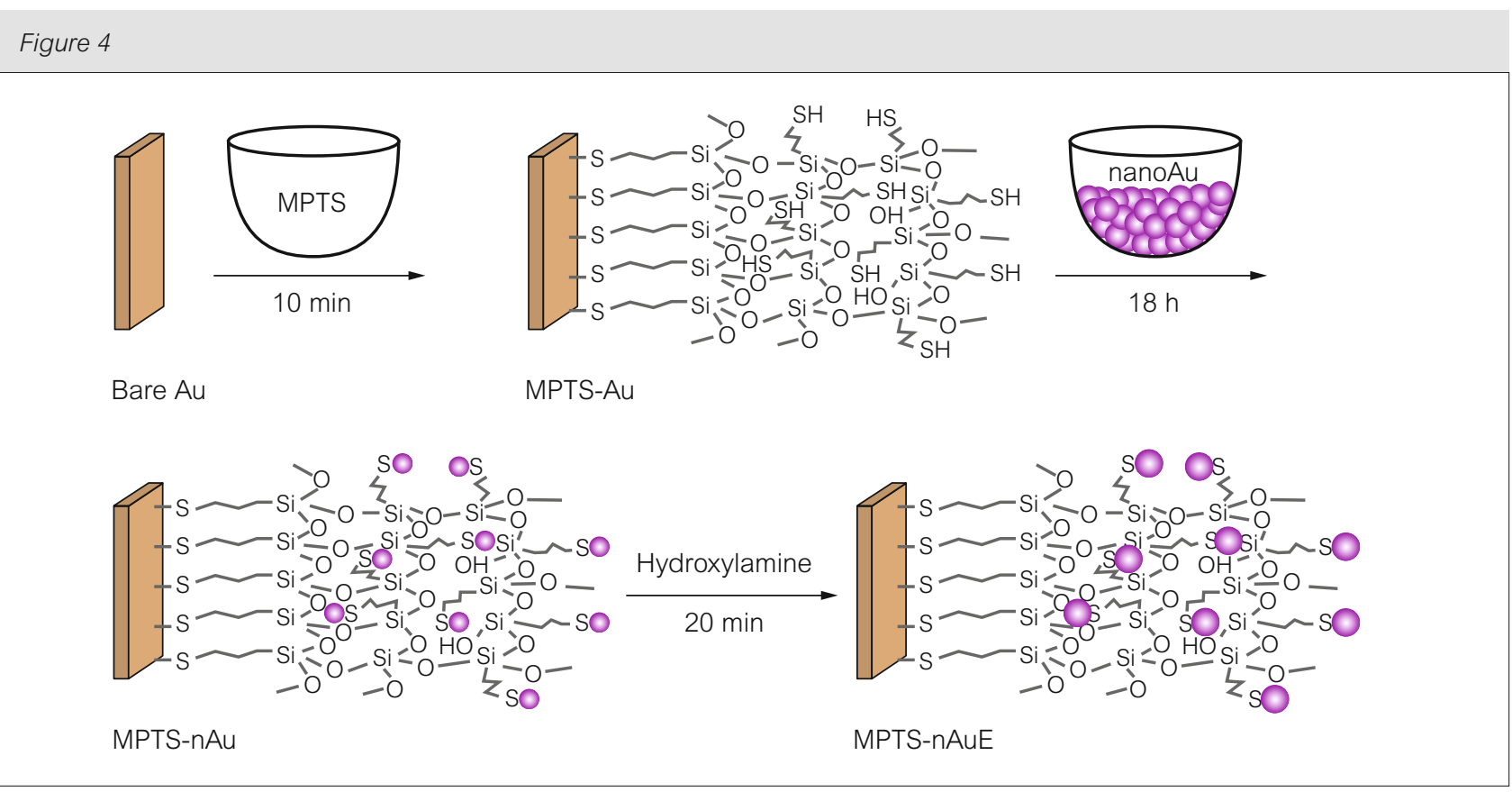

Construction of enzyme-free glucose biosensors by self-assembled of GNPs on a 3D silicate network. (From [119]. Reproduced with permission from Wiley-VCH Verlag $\mathrm{GmbH}$ \& Co. KGaA)

human IgG, onto the GNPs. This approach exhibited a linear response range to $\operatorname{lgG}$ between 0.125 and $80 \mathrm{ng} / \mathrm{mL}$ with a detection limit of $40 \mathrm{pg} / \mathrm{mL}$ [101].

\subsubsection{GNPs act as electrocatalyst}

While bulk gold is chemical inert, recent studies show that nanosized GNPs exhibit extraordinary catalytic activity [102-104], which is utilized by several studies in electrochemical biosensing [105-109]. The catalytic properties of GNPs, which are believed to originate from the quantum scale dimension [110], the large surface-to-volume ratio and the interface-dominated properties [111, 112], can decrease overpotentials of many analytically important electrochemical reactions, realize the reversibility of some redox reactions, and might even allow fabrication of enzyme-free biosensors. A recent research reported by Tuener et al. [113] has studied the effect of GNPs' diameter and supported material on the catalytic activity of GNPs. They showed that very small gold entities $(\sim 1.4 \mathrm{~nm})$ derived from 55-atom gold clusters and support materials are efficient and robust catalysts for the selective oxidation of styrene by dioxygen. A sharp size threshold in catalytic activity, where particles with diameters of $2 \mathrm{~nm}$ and above are completely inactive, was also determined. Their observations suggested that catalytic activity arises from the altered electronic structure intrinsic to small gold nanoparticles.
An electrocatalytic oxidation of NADH by GNPs on a gold electrode, demonstrated by Raj et al., underpins the catalytic activity of nanosized gold [114]. The biosensor was fabricated by self assembling of GNPs on a (3-mercaptopropyl)-trimethoxysilane (MPTS) modified polycrystalline gold (polygold) electrode. The GNPs self-assembled polygold-MPTS electrode showed a decrease in overpotential of $780 \mathrm{mV}$ in the presence of NADH without any electron transfer mediators [114]. The catalytic effect of GNPs was explained by the oxidation effect of surface oxides, which originated from the unusually oxidation of GNPs at low potential. A more detailed study similar to this case was reported by the same group later [115]. Nitric oxide electrochemical sensors fabricated on GNPs modified platinum microelectrode [116] or dense GNP film modified electrode [117] were also reported to be based on the catalytic oxidation of GNPs.

The GNPs catalysis of oxidation and reduction of $\mathrm{H}_{2} \mathrm{O}_{2}$ could be applied to develop biosensors for several kinds of analysts, for example, glucose. Bharathi and co-workers reported a glucose biosensor based on the electrodeposited biocomposites of GNPs and glucose oxidase enzyme [118]. Furthermore, the GNPs could also be utilized to fabricate enzyme-free biosensors. For instance, an enzyme-free glucose biosensors was reported to be constructed by the combination of self-assembling technique and 


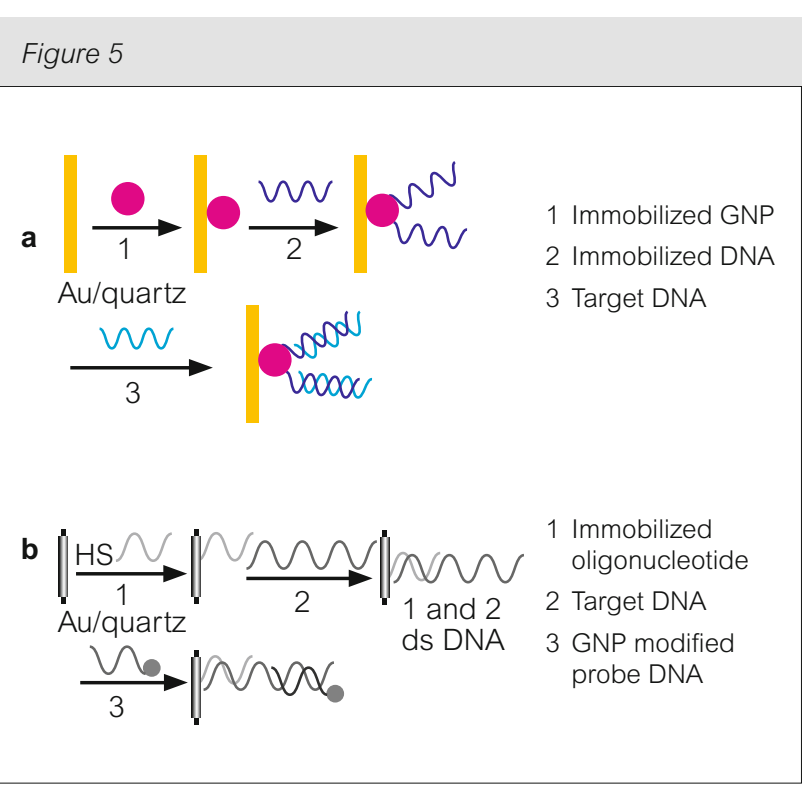

Schemes of two amplified DNA microgravimetric biosensors by GNPs. (a) Immobilization of GNPs on gold surface of QCM [129]; (b) Modification of DNA with GNPs. (From [130]. Reproduced with permission from The Royal Society of Chemistry)

sol-gel technique for immobilization of GNPs [119] (Fig. 4). In this study, the GNPs were self-assembled on a 3D silicate network on a gold electrode. As the GNPs were distributed both inside the sol-gel network and on the electrode surface, the active sites of GNPs effectively partake in the catalytic oxidation process, which made the GNPs act like a nanoscale electrode and provide a conduction pathway.

The catalysis of GNPs also exhibits selectivity, which enables selective electrochemical analysis. Ohsaka and coworkers developed an electrochemical sensor for selective detection of dopamine in the presence of ascorbic acid [120]. The catalytic effect of GNPs on the ascorbate oxidation, which resulted in the decrease of the oxidation overpotential of ascorbic acid and the effective separation of the oxidation potentials of ascorbic acid and dopamine, allow the selective electrochemical detection.

The three paragraphs above have summarized some different roles that GNPs play in electrochemical biosensors. However, the unique and attractive properties of GNPs present several opportunities to provide better analytical characteristics for electrochemical biosensing, which are not confined to the three categories. For example, GNPs can act as biomolecule tracers to stabilize the biomolecules, retain the bioactivity, and enhance the sensitivity
[121-123]. Nevertheless, the GNPs are always initially in suspension in this case, which is beyond the scope of this review. So this field is not discussed herein. Another point needs to be illustrated is that charming properties of GNPs enable them to play more than one role in one electrochemical biosensor. For instance, the large surface area, good biocompatibility, and conductivity properties are always utilized at the same time to improve the electrochemical analytical characteristics $[88,124-128]$.

\subsection{GNP-based piezoelectric biosensors}

Piezoelectric biosensors measure the mass change arising from the biological recognition process. The piezoelectric effect, which described the relation between a mechanical stress and an electrical change in solid, was first discovered in 1880 by the Jacques and Pierre Curie brothers. They observed that when a mechanical stress was applied on crystals, electrical changes appeared, and this voltage was proportional to the stress. They also verified the converse piezoelectric effect that a voltage across these crystals caused a corresponding mechanical stress.

Many types of materials, such as tourmaline, topaz or quartz show the piezoelectric effect. but the most common type used in piezoelectric analysis is quartz. The quartz crystal microbalance (QCM) is one of the most important techniques based on piezoelectric effect. However, for biosensing, in which the target detection molecules are always in trace quantity, the sensitivity of QCM remains to be further enhanced. As the high density and high surface-to-volume ratio of GNPs can amplify the mass change on the crystals during the analysis, numerous research groups focus on improving the analytical sensitivity by coupling GNPs with the QCM sensing process. In 2000, Jiang's [129] and Li's group [130] reported amplified DNA microgravimetric sensor by GNPs (Fig. 5). Given that the crystals of higher frequencies were difficult to remain frequency stable, both of them considered that amplifying the mass change on the electrode was more suitable to lower the detection limit. Li and his co-workers developed a sandwich-type ternary complex consisting of an oligodeoxynucleotide (ODN) immobilized on a QCM electrode, a target DNA and a GNP modified DNA, in which the latter two oligonucleotides were both complementary to the ODN (Fig. 5b). By interaction of the ODN and target DNA complex with four different oligonucleotides (GNP modified DNA complementary to ODN, DNA complementary to ODN (no GNP), 
GNP modified DNA complementary to ODN with a five-base mutation, and GNP modified DNA not complementary to ODN), they concluded that the GNP which was binding to the ODN served to enhance the signals. It was considered that in comparison to the masses of the binding pair members themselves, the relatively large mass of each GNP contributed to amplify the frequency shift and substantially extend the limits of sensitivity of the QCM detection system [130]. Different from Li's group, Jiang et al. immobilized GNPs onto the gold surface of QCM, followed by immobilization of 17 mer-oligonucleotide probes onto the GNPs (Fig.5a). The target DNA was detected by hybridization reaction with the probes. The relatively large surface area of the GNPs was considered to immobilize more probes onto the gold surface of the QCM, and thereby enhance the sensitivity [129]. Based on this work, Jiang's group developed a series of DNA QCM biosensors using GNPs as amplification tags [131-134], and the lowest detection limit of DNA obtained was $10^{-16} \mathrm{~mol} / \mathrm{L}$ [134]. GNPs are also successfully used as amplification tags in some other DNA piezoelectric biosensors, such as a DNA point mutation detection method based on DNA ligase reaction and GNP amplification [135], single-base mismatches detection using GNP-catalyzed deposition of gold on GNP-avidin conjugate to amplify the signals $[136,137]$, and Enterohemorrhagic Escherichia coli O157:H7 real-time detection using GNPs as a mass enhancer [138].

Another interesting research area based on GNPs and QCM is immuno-sensing or ligand-sensing. For example, a dendritic amplification immunoassay using GNP immunocomplex successfully detected as low as $3.5 \mathrm{ng} / \mathrm{mL}$ human $\mathrm{IgG}$ [139]. The method immobilized goat anti-human IgG on the gold electrode surface of QCM via pre-assembled protein $A$. The dendritic amplification process was implemented by interaction of the goat anti-human IgG with IgG-functionalized GNPs, and the subsequently interaction with the immunocomplex of protein A- and IgG-modified GNPs. Compared to the direct QCM determination without amplification, this assay lowers the detection limit by three orders of magnitude [139]. Nevertheless, the analysis time of the method, which was another important property of immunosensor, was relatively long. Similarly, by employing a strepavidin-biotin interaction as a model system, Kim et al. reported a sensitive biosensor using GNPs as signal amplification tags [140].
From these examples and other GNP-based piezoelectric biosensors, the mechanisms of the sensitivity enhancement contribution of GNPs can be summarized as follows: Surface enhancement effect and mass enhancement effect. A piezoelectric sensor is mass-sensitive device, which means any strategies that amplify the mass change will improve the analytical sensitivity. The quantity and activity of biological recognition elements immobilized on the sensing surface of piezoelectric biosensors determines sensitivity as well as the regeneration ability. The high surface area-to-volume ratio and biocompatibility of GNPs, which provide a very large number of interaction sites, make GNPs potential candidates to amplify the sensing surface area and maintain the sensing bioactivity, thereby enhance the quantity and activity of biological recognition elements $[129,132,136]$. Moreover the excellent biocompatible can improve the stability of the biological recognition and the relatively high density of GNP allows application as a mass enhancer [130, 131, 133-135, 137, 138, 140, 141]. The mass amplification is generally implemented via modification or interaction of the analyte adsorbed onto the sensing surface of GNPs. In addition, the dendritic amplification technique [139] and in situ catalyzed growth of GNPs $[137,142]$ can enhance the mass change at a much larger scale.

Conjugation of GNPs with other nanomaterials also gains much interest in piezoelectric biosensors. In this context, hydroxyapatite $\left(\mathrm{HA}, \mathrm{Ca}_{5}\left(\mathrm{PO}_{4}\right)_{3}(\mathrm{OH})\right)$, a bioceramic analogous to the mineral component of bone with great biocompatibility and particular multi-adsorbing sites, has attracted a lot of attention. For instance, a GNP/HA hybrid nanomaterial was developed and used as substrate to immobilize the recognition reagent [143]. The new hybrid material shows particular structure with multi-adsorbing sites and multifunctional advantages such as high surface area, satisfactory biocompatibility, good solubility and dispersibility, which not only allows a large amount of recognition reagent to be loaded, but also gives the immobilized recognition reagent more freedom in orientation. The employment of GNP/HA hybrid nanomaterial in QCM endowed an alphafetoprotein immunosensor with a remarkably higher sensitivity than that used only GNP or HA [143]. By incorporation of $\gamma-\mathrm{Fe}_{2} \mathrm{O}_{3}$, a magnetic material which allows magnetic separation, into the GNP/HA hybrid nanomaterial, a reusable piezoelectric immunosensor using antibody-adsorbed magnetic nanocomposite was developed by the same lab recently [144]. 


\section{Summary and outlook}

The unique and superior properties of GNPs have shown strong potential for the development of analytical systems with attractive and promising analytical behaviors. The studies described above demonstrated the advantageous performances of GNPs for three main types of biosensor. Whatever roles the GNPs play in the process of biosensing, they provide much better analytical performances for biosensors in term of sensitivity, selectivity, reliability etc. However, this rapidly extending area is still in its infancy from the viewpoint of practical, realworld applications, and the widespread practical application of GNPs-based biosensor is not possible currently. There remain challenges to be addressed before the full potential of GNPs for biosensor applications can be realized. In order to fully exploit the potential application of GNPs in biosensor, design of GNPs based biosensors for high throughput and multiplexed identification of biomarkers should be given attention. Another promising research direction is the production of GNPs with long-term stability in various environments. In addition, as size and nanostructure greatly effects on the optical and electrical properties of GNPs, researches on design and synthesis of GNPs with well-defined geometry and properties will promote the application of GNPs in biosensors. Compositing GNPs with other nanomaterials is also an intriguing direction. With the enormous emerging nanomaterials, hybrids of GNPs and other nanomaterials may display distinct properties. In addition to exploration of new structure or new composition, effort in improving the analytical performance at the present stage, such as preventing nonspecific adsorption of biomolecules onto GNPs, or shorten the analysis time, also deserves the full attention.

\section{Acknowledgement}

This work was supported by National Science Foundation of China (20677018, 20807017 and 30872125) and a grant from the German Academic Exchange Service (DAAD) and Chinese Scholarship Council (CSC).

\section{About the authors}

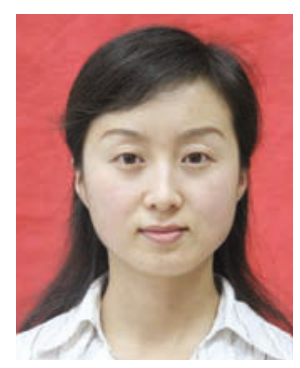

Yuanyuan Li received her BS and PhD degree in environmental hygiene from Huazhong University of Science and Technology in 2002 and 2007 respectively. She then works as a lecture in Tongji medical college, Huazhong University of Science and Technology.

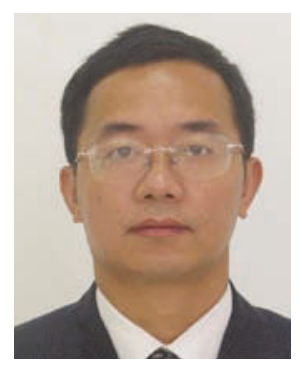

Prof. Shunqing $\mathbf{X u}$ received his BS and PhD degree in environmental hygiene from Tongji medical university in 1988 and 1993 respectively. He then worked there (Tongji medical college, Huazhong University of Science and Technology from 2000) and was promoted to Professor in 2000. His research interests include nanoparticles, biosensors and bioassays for environmental pollutant, and biomarkers for environmental toxicology.

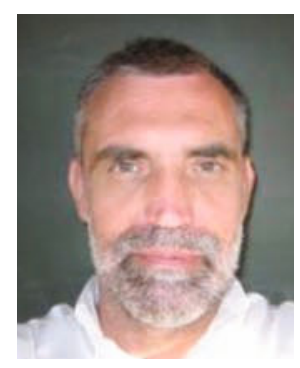

Professor Dr. Hermann Josef

Schluesener received his Ph.D degree in Biolog from University of Bochum in Germany in 1981. He then worked as a postdoctoral fellow at the Sandoz Institute of Biochemistry in Austria (1985-1986) and Center for Neurologic Disesases at Harvard Medical School (1986-1988). From 1989-1992 he was the head of Cell Biology in the Clinical Research Unit for Multiple Sclerosis at University of Wuerzburg, Germany. Since 1992, he has been the Vice Director of Institute of Brain Research and Director of Sub-department of Immunopathology of the Nervous System at University of Tuebingen. He has also been the Director of the Steinbeis Center of Regenerative Medicine at Institute of Brain Research at University of Tuebingen since 2003. His major areas of research include neuroinflamnation in trauma, autoimmune, infective, degenerative, and neoplastic diseases of the CNS and PNS. 


\section{References}

1 L.C. Clark, Jr. and C. Lyons, Ann NY Acad Sci, 1962, 102, 29

2 T. Vo-Dinh and B. Cullum, Fresenius J Anal Chem, 2000, 366, 540

3 K.K. Jain, Med Device Technol, 2003, 14, 10

4 Y. Xiao, F. Patolsky, E. Katz, J.F. Hainfeld and I. Willner, Science, 2003, 299, 1877

5 M. Schierhorn, S.J. Lee, S.W. Boettcher, G.D. Stucky and M. Moskovits, Advanced Materials, 2006, 18, 2829

6 H. Cai, Y. Xu, N. Zhu, P. He and Y. Fang, Analyst, 2002, 127, 803

7 X.L. Luo, J.J. Xu, W. Zhao and H.Y. Chen, Biosens Bioelectron, 2004, 19, 1295

8 J. Wang, G. Liu, R. Polsky and A. Merkoçi, Electrochemistry Communications, 2002, 2, 722

9 X. Luo, A. Morrin, A.J. Killard and M.R. Smyth, Electroanalysis, 2006, 18, 319

10 J. Wang, R. Polsky and D. Xu, Langmuir, 2001, 17, 5739

11 J. Wang, D. Xu and R. Polsky, J Am Chem Soc, 2002, 124, 4208

12 J. Liu and Y. Lu, J Am Chem Soc, 2003, 125, 6642

13 Y. Qi, B. Li and Z. Zhang, Biosensors and Bioelectronics, 2009, 24, 3581

14 C.J. Murphy, A.M. Gole, S.E. Hunyadi, J.W. Stone, P.N. Sisco, A. Alkilany, B.E. Kinard and P. Hankins, Chem Commun (Camb), 2008, 544

15 M.C. Daniel and D. Astruc, Chem Rev, 2004, 104, 293

16 M. Hu, J. Chen, Z.Y. Li, L. Au, G.V. Hartland, X. Li, M. Marquez and Y. Xia, Chem Soc Rev, 2006, 35, 1084

17 S. Link and M.A. El-Sayed, J. Phys. Chem. B, 1996, 103, 8410

18 P. Mulvaney, Langmuir, 1996, 12, 788

19 P. Englebienne, The Analyst, 1998, 123, 1599

20 I.M. Klotz, Q Rev Biophys, 1985, 18, 227

21 D. Eck and C.A. Helm, Langmuir, 2001, 17, 957

22 N. Nath and A. Chilkoti, Anal Chem, 2002, 74, 504

23 N. Nath and A. Chilkoti, Anal Chem, 2004, 76, 5370

24 Z.M. Qi, I. Honma and H. Zhou, Opt Lett, 2006, 31, 1854

25 H.Y. Lin, C.T. Chen and Y.C. Chen, Anal Chem, 2006, 78, 6873

26 T. Okamoto, I. Yamaguchi and T. Kobayashi, Opt Lett, 2000, 25, 372

27 P. Englebienne, Van Hoonacker and J. Valsamis, Clin Chem, 2000, 46, 2000

28 L.K. Chau, Y.F. Lin, S.F. Cheng and T.J. Lin, Sensors and Actuators B: Chemical, 2006, 113, 100

29 M.P. Jonsson, P. Jonsson, A.B. Dahlin and F. Hook, Nano Lett, 2007, 7, 3462

30 S.M. Marinakos, S. Chen and A. Chilkoti, Anal Chem, 2007, 79, 5278

31 T. Endoa, S. Yamamurab, K. Kermanc and E. Tamiyab, Analytica Chimica Acta, 2008, 614, 182
32 S. Takae, Y. Akiyama, Y. Yamasaki, Y. Nagasaki and K. Kataoka, Bioconjug Chem, 2007, 18, 1241

33 L.A. Lyon, M.D. Musick and M.J. Natan, Anal Chem, 1998, 70, 5177

34 L. He, M.D. Musick, S.R. Nicewarner, F.G. Salinas, S.J. Benkovic, M.J. Natan and C.D. Keating, Journal of the American Chemical Society, 2000, 122, 9071

35 E. Hutter, S. Cha, J.F. Liu, J. Park, J. Yi, J.H. Fendler and D. Roy, The Journal of Physical Chemistry B, 2001, 105, 8

36 X. Yang, Q. Wang, K. Wang, W. Tan and H. Li, Biosens Bioelectron, 2007, 22, 1106

37 L.A. Lyon, M.D Musick, P.C. Smith, B.D. Reiss, D.J. Peña and M.J. Natan, Sensors and Actuators B: Chemical, 1999, 54, 118

38 E. Fua, S. A, R. b and P. Yager, Analytica Chimica Acta, 2007, 599, 118

39 C. Cao and S.J. Sim, Biosens Bioelectron, 2007, 22, 1874

40 E. Fu, S.A. Ramsey and P. Yager, Analytica Chimica Acta, 2007, 599, 118

41 L.A. Lyon, M.D. Musick, P.C. Smith, B.D. Reiss, D.J. Peña and M.J. Natan, Sensors and Actuators B: Chemical, 1999, 54, 118

42 G. Xu, H. Li, X. Ma, X. Jia, J. Dong and W. Qian, Biosens Bioelectron, 2009, 25, 362

43 T.J. Lin, K.T. Huang and C.Y. Liu, Biosens Bioelectron, 2006, 22, 513

44 Y. Li, A.W. Wark, H.J. Lee and R.M. Corn, Anal Chem, 2006, 78, 3158

45 Y. Lei, H. Chen, H. Dai, Z. Zeng, Y. Lin, F. Zhou and D. Pang, Biosens Bioelectron, 2008, 23, 1200

46 Y. Luo, F. Yu and R.N. Zare, Lab Chip, 2008, 8, 694

47 J. Matsui, K. Akamatsu, N. Hara, D. Miyoshi, H. Nawafune, K. Tamaki and N. Sugimoto, Anal Chem, 2005, 77, 4282

48 Y. Sato, K. Sato, K. Hosokawa and M. Maeda, Anal Biochem, 2006, 355, 125

49 M. Zayats, A.B. Kharitonov, S.P. Pogorelova, O. Lioubashevski, E. Katz and I. Willner, J Am Chem Soc, 2003, 125, 16006

50 Y.T. Tseng, Y.J. Chuang, Y.C. Wu, C.S. Yang, M.C. Wang and F.G. Tseng, Nanotechnology, 2008, 19, 345501

51 M.K. Hossain, G.G. Huang, T. Kaneko and Y. Ozaki, Phys Chem Chem Phys, 2009, 11, 7484

52 Y.C. Cao, R. Jin and C.A. Mirkin, Science, 2002, 297, 1536

53 E. Katz, I. Willner and J. Wang, Electroanalysis, 2004, 16, 19

54 A. Amine, J.M. Kauffmann, G.G. Guilbault and S. Bacha, Analytical Letters, 1993, 26, 1281

55 T. Ikeda, H. Hamada, K. Miki and M. Senda, Agricultural and Biological Chemistry 1985, 49, 541

56 J. Losada and M.P.G. Armada, Electroanalysis, 1997, 9, 1416

57 K.R. Brown, A.P. Fox and M.J. Natan, Journal of the American Chemical Society, 1996, 118, 1154

58 J. Lin, W. Qu and S. Zhang, Anal Biochem, 2007, 360, 288 
59 T. Tangkuaram, C. Ponchio, T. Kangkasomboon, P. Katikawong and W. Veerasai, Biosens Bioelectron, 2007, 22, 2071

60 V.V. Shumyantseva, S. Carrara, V. Bavastrello, D. Jason Riley, T.V. Bulko, K.G. Skryabin, A.I. Archakov and C. Nicolini, Biosens Bioelectron, 2005, 21, 217

61 Q. Xu, C. Mao, N.N. Liu, J.J. Zhu and J. Sheng, Biosens Bioelectron, 2006, 22, 768

62 J. Jia, B. Wang, A. Wu, G. Cheng, Z. Li and S. Dong, Anal Chem, 2002, 74, 2217

63 L. Zhang, X. Jiang, E. Wang and S. Dong, Biosens Bioelectron, 2005, 21, 337

64 V. Carralero, M.L. Mena, A. Gonzalez-Cortes, P. YanezSedeno and J.M. Pingarron, Biosens Bioelectron, 2006, 22, 730

65 S. Liu, L. Peng, X. Yang, Y. Wu and L. He, Anal Biochem, 2008, 375, 209

66 L. Zhang, R. Yuan, Y. Chai and X. Li, Anal Chim Acta, 2007, 596, 99

67 S. Liu and H. Ju, Biosens Bioelectron, 2003, 19, 177

68 X.L. Luo, J.J. Xu, Y. Du and H.Y. Chen, Anal Biochem, 2004, 334, 284

69 M.H. Xue, Q. Xu, M. Zhou and J.J. Zhu, Electrochemistry Communications, 2006, 8, 1468

70 R. Shenhar, T.B. Norsten and V.M. Rotello, Advanced Materials, 2005, 17, 6570669

71 F. Gao, R. Yuan, Y. Chai, S. Chen, S. Cao and M. Tang, J Biochem Biophys Methods, 2007, 70, 407

72 G. Yang, R. Yuan and Y.Q. Chai, Colloids Surf B Biointerfaces, 2008, 61, 93

73 W. Li, R. Yuan, Y. Chai, L. Zhou, S. Chen and N. Li, J Biochem Biophys Methods, 2008, 70, 830

74 J. Njagi and S. Andreescu, Biosens Bioelectron, 2007, 23, 168

75 J. Wu, F. Yan, X. Zhang, Y. Yan, J. Tang and H. Ju, Clin Chem, 2008, 54, 1481

76 A. Gole, C. Dash, V. Ramakrishnan, S.R. Sainkar, A.B. Mandale, M. Rao and M. Sastry, Langmuir, 2001, 17, 1674

77 A. Gole, S. Vyas, S. Phadtare, A. Lachke and M. Sastry, Colloids and Surfaces B: Biointerfaces, 2002, 25, 129

78 M. Yang, J. Jiang, Y. Lu, Y. He, G. Shen and R. Yu, Biomaterials, 2007, 28, 3408

79 D. Du, S. Chen, J. Cai and A. Zhang, Biosens Bioelectron, 2007, 23, 130

80 L. Lu and X. Lin, Anal Sci, 2004, 20, 527

81 L. Tang, G.M. Zeng, G.L. Shen, Y.P. Li, Y. Zhang and D.L. Huang, Environ Sci Technol, 2008, 42, 1207

82 S. Andreescu and L.A. Luck, Anal Biochem, 2008, 375, 282

83 X.L. Luo, J.J. Xu, Q. Zhang, G.J. Yang and H.Y. Chen, Biosens Bioelectron, 2005, 21, 190

84 F. Patolsky, T. Gabriel and I. Willner, Journal of Electroanalytical Chemistry, 1999, 479, 69

85 Z.M. Liu, H. Wang, Y. Yang, H.F. Yang, S.Q. Hu, G.L. Shen and R.Q. Yu, Analytical Letters, 2004, 37, 1079

86 T. Yin, W. Wei, L. Yang, K. Liu and X. Gao, J Biochem Biophys Methods, 2007, 70, 587

87 C.X. Lei, S.Q. Hu, N. Gao, G.L. Shen and R.Q. Yu, Bioelectrochemistry, 2004, 65, 33

88 S. Zhao, K. Zhang, Y. Bai, W. Yang and C. Sun, Bioelectrochemistry, 2006, 69, 158

89 S. Zhang, N. Wang, H. Yu, Y. Niu and C. Sun, Bioelectrochemistry, 2005, 67, 15

90 X. Li, R. Yuan, Y. Chai, L. Zhang, Y. Zhuo and Y. Zhang, J Biotechnol, 2006, 123, 356

91 Y. Du, X.L. Luo, J.J. Xu and H.Y. Chen, Bioelectrochemistry, 2007, 70, 342

92 S. Li, R. Zhang, P. Li, W. Yi, Z. Zhang, S. Chen, S. Su, L. Zhao and C. Hu, Int Immunopharmacol, 2008, 8, 859

93 I. Robert, A. Reynolds, C.A. Mirkin and R.L. Letsinger, Journal of the American Chemical Society, 2000, 122, 3795

94 R. Jin, G. Wu, Z. Li, C.A. Mirkin and G.C. Schatz, J Am Chem Soc, 2003, 125, 1643

95 J. Kang, X. Li, G. Wu, Z. Wang and X. Lu, Anal Biochem, 2007, 364, 165

96 H. Cai, C. Xu, P. He and Y. Fang, Journal of Electroanalytical Chemistry, 2001, 510, 78

97 J. Li, T. Han, N. Wei, J. Du and X. Zhao, Biosensors and Bioelectronics 2009, 25, 773

98 Y. Wei, Y. Li, N. Zhang, G. Shi and L. Jin, Ultrason Sonochem, 2009, 17, 17

99 H. Wang, X. Wang, X. Zhang, X. Qin, Z. Zhao, Z. Miao, N. Huang and Q. Chen, Biosens Bioelectron, 2009, 25, 142

100 Y. Zhang, J. Wang and M. Xu, Colloids Surf B Biointerfaces, 2009, Article in Press

101 R. Cui, H. Huang, Z. Yin, D. Gao and J.J. Zhu, Biosens Bioelectron, 2008, 23, 1666

102 M. Valden, X. Lai and D.W. Goodman, Science, 1998, 281, 1647

103 Y. Lou, M.M. Maye, L. Han, J. Luo and C.-J. Zhong, Chemical Communications, 2001, 473

104 M.S. El-Deab, T. Okajima and T. Ohsaka, Journal of The Electrochemical Society 2003, 150, A851

105 Q. Kang, L. Yang and Q. Cai, Bioelectrochemistry, 2008, 74, 62

106 Y. Kong, H. Chen, Y. Wang and S.A. Soper, Electrophoresis, 2006, 27, 2940

107 A.I. Abdelrahman, A.M. Mohammad, T. Okajima and T. Ohsaka, J Phys Chem B, 2006, 110, 2798

108 G. Liu, Y.Y. Lin, H. Wu and Y. Lin, Environ Sci Technol, 2007, 41, 8129

109 N. Zhou, J. Wang, T. Chen, Z. Yu and G. Li, Anal Chem, 2006, 78, 5227

110 A.P. Alivisatos, Science, 1996, 271, 933

111 M.M. Maye, Y. Lou and C.J. Zhong, Langmuir, 2000, 16, 7520

112 M. Haruta and M. Daté, Applied Catalysis A: General, 2001, 222, 427 
113 M. Turner, V.B. Golovko, O.P. Vaughan, P. Abdulkin, A. Berenguer-Murcia, M.S. Tikhov, B.F. Johnson and R.M. Lambert, Nature, 2008, 454, 981

114 C.R. Raj and B.K. Jena, Chem Commun (Camb), 2005, 2005

115 B.K. Jena and C.R. Raj, Anal Chem, 2006, 78, 6332

116 M. Zhu, M. Liu, G. Shi, F. Xu, X. Ye, J. Chen, L. Jin and J. Jin, Analytica Chimica Acta, 2002, 455, 199

117 A. Yu, Z. Liang, J. Cho and F. Caruso, Nano Letters, 2003, 3, 1203

118 S. Bharathi and M. Nogami, Analyst, 2001, 126, 1919

119 B.K. Jena and C.R. Raj, Chemistry, 2006, 12, 2702

120 C.R. Raj, T. Okajima and T. Ohsaka, J. Electroanal. Chem., 2003, 543, 127

121 J. Wang, D. Xu, A.N. Kawde and R. Polsky, Anal Chem, 2001, 73, 5576

122 L. Authier, C. Grossiord, P. Brossier and B. Limoges, Anal Chem, 2001, 73, 4450

123 M. Dequaire, C. Degrand and B. Limoges, Anal Chem, 2000, 72, 5521

124 J.D. Qiu, H.Z. Peng, R.P. Liang, J. Li and X.H. Xia, Langmuir, 2007, 23, 2133

125 J. Li and X.Q. Lin, Anal Chim Acta, 2007, 596, 222

126 B.Y. Wu, S.H. Hou, F. Yin, Z.X. Zhao, Y.Y. Wang, X.S. Wang and Q. Chen, Biosens Bioelectron, 2007, 22, 2854

127 S. Xu, G. Tu, B. Peng and X. Han, Anal Chim Acta, 2006, $\mathbf{5 7 0}, 151$

128 S. Upadhyay, G.R. Rao, M.K. Sharma, B.K. Bhattacharya, V.K. Rao and R. Vijayaraghavan, Biosens Bioelectron, 2009, 25, 832

129 L. Lin, H. Zhao, J. Li, J. Tang, M. Duan and L. Jiang, Biochem Biophys Res Commun, 2000, 274, 817
130 X.C. Zhou, S.J. O'Shea and S.F.Y. Li, Chemical Communications, 2000, 953

131 H.Q. Zhao, L. Lin, J.R. Li, J.A. Tang, M.X. Duan and L. Jiang, Journal of Nanoparticle Research, 2001, 3, 321

132 Z. Hongqiu, L. Lin, T. Ji, D. Mingxing and J. Long, Chinese Science Bulletin, 2001, 46, 1074

133 T. Liu, J. Tang and L. Jiang, Biochem Biophys Res Commun, 2002, 295, 14

134 T. Liu, J. Tang and L. Jiang, Biochemical and Biophysical Research Communications, 2004, 313, 4

135 L. Pang, J. Li, J. Jiang, G. Shen and R. Yu, Anal Biochem, 2006, 358, 99

136 Y. Weizmann, F. Patolsky and I. Willner, Analyst, 2001, 126, 1502

137 I. Willner, F. Patolsky, Y. Weizmann and B. Willner, Talanta, 2002, 56, 847

138 S.H. Chen, V.C. Wu, Y.C. Chuang and C.S. Lin, J Microbiol Methods, 2008, 73, 7

139 X. Chu, Z.L. Zhao, G.L. Shen and R.Q. Yu, Sensors and Actuators B, 2006, 114, 696

140 N.H. Kim, T.J. Baek, H.G. Park and G.H. Seong, Anal Sci, 2007, 23, 177

141 Z.D. Liu, Y. F. Li, J. Ling and C.Z. Huang, Environ Sci Technol, 2009, 43, 5022

142 Q. Zhang, Y. Huang, R. Zhao, G. Liu and Y. Chen, J Colloid Interface Sci, 2008, 319, 94

143 Y. Ding, J. Liu, H. Wang, G. Shen and R. Yu, Biomaterials, 2007, 28, 2147

144 Y. Zhang, H. Wang, B. Yan, Y. Zhang, J. Li, G. Shen and R. Yu, Journal of Immunological Methods, 2008, 332, 103 